\title{
Media Review
}

\section{Anti-Bullying Websites}

John Caruso Jr. Media Review Editor

In October 2006, PACER's National Bullying Prevention Center organized a week of anti-bullying awareness and activities. Their program continued and resulted in October being designated as National Bullying Prevention Awareness Month in the United States. In the past nine years, identification and prevention of bullying has proliferated and drawn support from numerous private and government organizations.

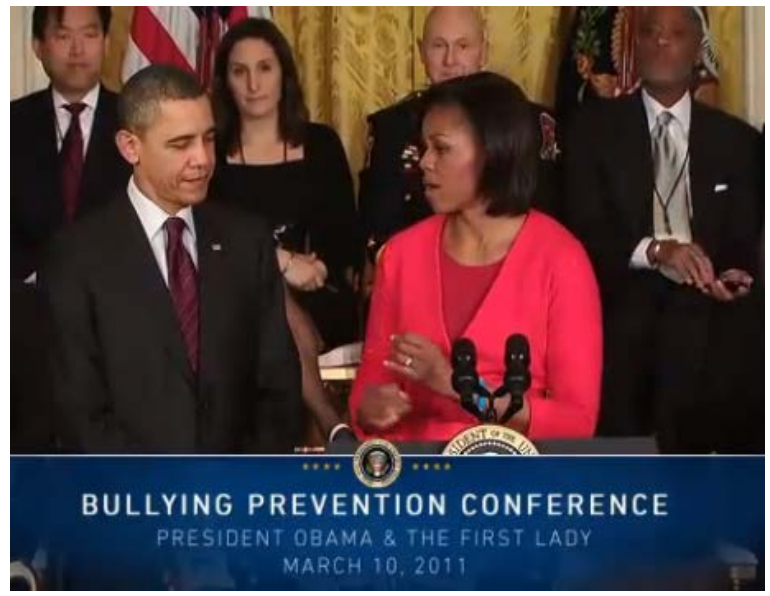

In March 2011, President Barack Obama and First Lady Michele Obama hosted the first national bullying prevention conference at the White House and announced the creation of a federally sponsored anti-bullying website http://stopbullying.gov/. The website provides an operational definition of bullying, which includes physical, verbal, visual and, most recently, cyberbullying in social media. There are multiple definitions, aspects, and indicators of bullying which continue to evolve.

Some of the characteristics of bullying in K-12 school settings include unwanted, aggressive behavior that involves a real or perceived power imbalance. The behavior is repeated or has the potential to reoccur. Students who are bullied or who bully others generally have serious, lasting attitudinal problems. To be considered bullying, the behavior must be aggressive and include an imbalance of power. Students who bully use their power-such as physical strength, access to sensitive information, or popularity - to control or hurt others. Power imbalances can change over time and in different situations, even if they involve the same students.

The causes of bullying are complex and reducing this potentially explosive issue is critical for K-12 schools. The 1999 Columbine High School killers, similar to an undergraduate student who killed victims at Virginia Polytech in 2007, had been bullied 
in school. The 2012 Sandy Hook Elementary School massacre of students and staff members in Newtown, CT, was conducted by a former student who was bullied in the same school. Child psychologists estimate that, at some time in their school lives, $40 \%$ of American students are excluded, rejected, teased, picked on, or severely bullied. In 2014 , it is estimated, 13,000,000 K-12 students were bullied in school and 3 million stayed home fearing being bullied. One problem with verifying bullying statistics is that $40 \%$ of bullying incidents go unreported. Some parents have enrolled their children in online academies to avoid face-to-face bullying, but the taunting and teasing can continue online via social media.

The U.S. national statistics reports the following (National Statistics on Bullying 2014, http://nobullying.com/bullying-statistics-2014/):

\section{Been Bullied}

- $28 \%$ of U.S. students in grades 6-12 experienced bullying.

- $20 \%$ of U.S. students in grades 9-12 experienced bullying.

\section{Bullied Others}

- Approximately $30 \%$ of young people admit to bullying others.

\section{Seen Bullying}

- $71 \%$ of young people say they have seen bullying in their schools.

- $70 \%$ of school staff have seen bullying.

- When bystanders intervene, bullying stops within 10 seconds $57 \%$ of the time.

\section{Been Cyberbullied}

- $9 \%$ of students in grades 6-12 experienced cyberbullying.

- $15 \%$ of high school students (grades 9-12) were digitally bullied in the past year.

- 55\% of LGBT students experienced cyberbullying.

\section{How Often Bullied}

- $41 \%$ of students reported some type of frequent involvement in bullying.

\section{Types of Bullying}

- The most common types of bullying are verbal and social.

- Physical bullying is occurring less often while cyberbullying is increasing.

- By middle school the following percentages of students had experienced these types of bullying: name calling (44\%); teasing (43\%); spreading rumors or lies (36\%); pushing or shoving (32\%); hitting, slapping, or kicking (29\%); leaving out (29\%); threatening (27\%); stealing belongings 
(27\%); sexual comments or gestures (24\%); e-mail or blogging (10\%) (http://www.stopbullying.gov/news/media/facts/ - ftn3).

\section{Where Bullying Occurs}

- Most bullying takes place in school, outside on school grounds, and on the school bus.

- Bullying happens wherever children gather in the community.

- Cyberbullying occurs on cell phones and online.

- Only 20 to $30 \%$ of students who are bullied notify adults.

Psychologists caution that bullying should never be accepted as normal behavior or part of maturing. Bullying is not a rite of passage. Exposure to bullying is related to increased dropout rates, lower self-esteem, social isolation, depression, declining grades, and increases in illness, suicide, and violent acts. A 2014 study by the Centers for Disease Control and Prevention says thousands of students who reported being bullied brought weapons to school. The report analyzed a survey of 15,000 high school students who were asked about bullying. The survey indicated 20 percent of those high school students reported being victims of bullying within the last 12 months. Most concerning was the estimate that, of the $13,000,000$ bullying victims, some 250,000 were carrying guns, knives, clubs, or some type of weapon to school for protection or revenge.

The National Conference of State Legislatures reported that between 2005 and 2015 all 50 states had passed a law defining, prohibiting, and punishing bullying. Unfortunately each state has different operational definitions and legal procedures for identifying and dealing with the many manifestations of bullying. There are numerous bullying prevention digital resources to assist educators, parents, students, school staff and other professionals. Three noteworthy websites and additional resources include the following:

Stop Bullying (http://www.stopbullying.gov/), the U.S. Department of Health and

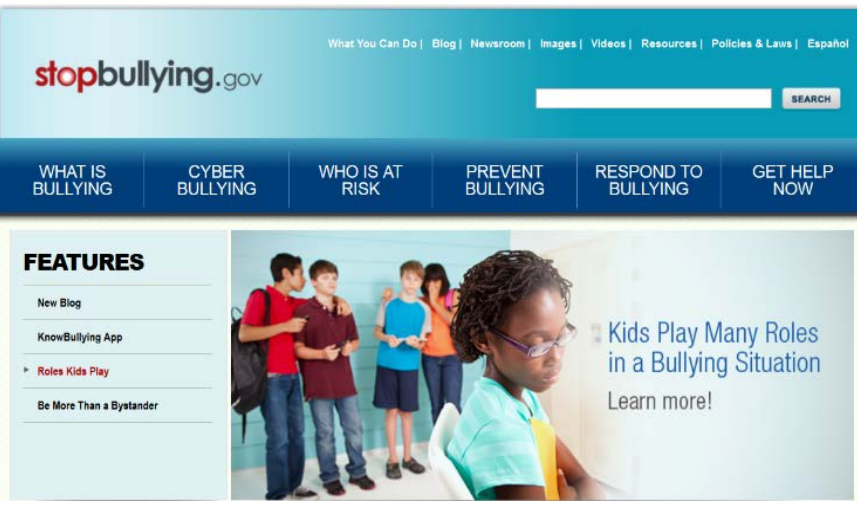
Human Services' (DHHS) anti-bullying website, was established by President Obama and is available in English and Spanish. The text size is adjustable for those with low vision. The six-item dropdown menu includes (1) what bullying means; (2) what consists of cyberbullying; (3) who is at risk of being bullied; (4) how bullying can be prevented; (5) how one can respond to bullying best, and (6) where one can find assistance. It provides an 800 -number to 
contact the National Suicide Prevention Center 24/7. Other resources include a blog, newsroom, images, videos, and an interactive map of all states, territories, and commonwealths that explains anti-bullying policies and laws. The video collection is extensive and contains 38 videos created over the last five years. The resource bank provides hotlinks to 275 bullying related items selected from the last 20 years.

Kids Against Bullying (http://www.pacerkidsagainstbullying.org/) is only available in English but offers access to an impressive array of current bullyingrelated resources updated each month. Its menu includes five links to (1) What is bullying; (2) Are you a target of bullying; (3) Do you bully; (4) How can you help; (5) Join the cause against bullying. One useful and unique feature of this website is entitled Ask Carmen, where 12 cartoon figures interact in vignettes

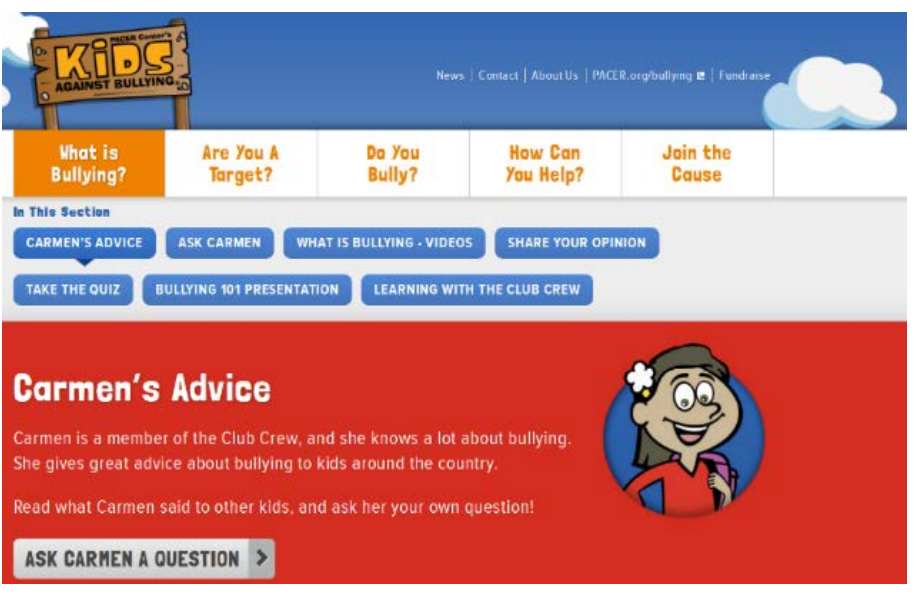
related to bullying. One young man named Brad is a bad person who likes to bully others. Others include a character in wheelchair with cerebral palsy, one with Down's syndrome, another with ADHD, and one with hearing loss. Another has a brother on the autism spectrum, and Carmen suffers from epilepsy. The website contains seven current videos about bullying and links to hundreds of resource

Stomp Out Bullying (http://www.stompoutbullying.org/) appears only in English and has an abbreviated menu similar to the previous two websites. This website has a dynamic design which allows users to access information from a variety of embedded hotlinks. The articles and resources range from 2009 to 2015, and 120 short videos from 2011 to 2015 are also included. Stomp Out Bullying invites students to selfnominate to become Teen Ambassadors in their schools and lead anti-bullying activities. They maintain a Helpchat hotline that offers daily assistance and advice for a total of 37 hours distributed over the week. The organization has 23 corporate sponsors and an equal number of celebrities who support their outreach programs.

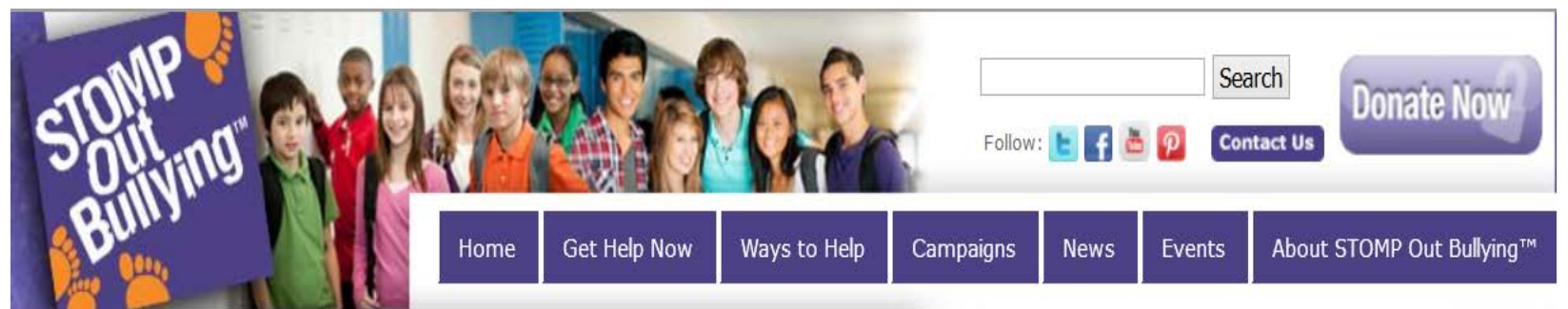


Additional anti-bullying resources for educators, staff, students, and parents include lesson plans and activities from the Southern Poverty Law Center's Teaching Tolerance project as well as videos and media hotlinks from PBS Combat Bullying with PBS LearningMedia Resources. "A Teachable Moment," a program of the Morningside Center, offers lesson plans and classroom activities to combat bullying. Common Sense Media has five videos that explain the nature of cyberbullying and how to fight it. The Gay, Lesbian, and Straight Education Network (GLSEN) hosts lesson plans on many aspects of prejudice, bias and discrimination at http://www.glsen.org/educate/ resources/lesson-plans. 